\section{Plasma 25-hydroxy vitamin D concentrations in patients with fractures of the femoral neck}

Fractures of the neck of the femur, which are common in the elderly, occur more often in women than in men and the incidence increases exponentially with age. ${ }^{1}$ The finding of histological osteomalacia in one-third of these patients ${ }^{2}$ : ${ }^{2}$ uggests that vitamin $\mathrm{D}$ deficiency may be an important causal factor, but no controlled study of vitamin $D$ status in these patients has been performed in Britain. We have studied 25-hydroxy vitamin D (25-OHD) concentrations in patients with fractures and in matched controls drawn from a home-based population-the source of most fractures.

\section{Patients, methods, and results}

Plasma $25-\mathrm{OHD}$ was measured by a radiocompetitive protein-binding assay ${ }^{4}$ in 98 white women aged 65 and over who were admitted to hospital consecutively with fractures of the neck of the femur. 25-OHD concentrations were also measured in 76 controls, matched for age and sex, who were drawn from a random sample of the Leeds population taken from the electoral register and demographically and socially representative of the sampling frame. The mean age $( \pm S D)$ of the patients was $80 \cdot 2 \pm 7 \cdot 3$ years and that of the controls $79 \cdot 4 \pm 7 \cdot 2$ years. A history of vitamin $\mathrm{D}$ in the diet was also obtained at interview from the patients and controls, and an environmental history was taken to calculate the time spent out of doors during the week preceding the interview ("sunlight exposure"). The investigation was extended through a year to exclude seasonal factors, and plasma samples from both groups were assayed together to exclude the effect of interassay variation on comparative analysis.

The mean plasma $25-\mathrm{OHD}$ concentration was significantly lower in the patients with fractures $(34.5 \pm 24.5 \mathrm{nmol} / 1 ; 13.8 \pm 9.8 \mathrm{ng} / \mathrm{ml})$ than in the controls $(55.8 \pm 33.8 \mathrm{nmol} / 1 ; 22.3+13.5 \mathrm{ng} / \mathrm{ml})(\mathrm{P}<0.001)$. Values below $25 \mathrm{nmol} / 1(10 \mathrm{ng} / \mathrm{ml})$ were found in $40 \%$ of patients and $17 \%$ of controls $(\mathbf{P}<0.001)\left(2 \times 2 \%^{2}\right.$ with Yates's correction $)$. The dietary intake of vitamin $D$ was also significantly lower in patients with fractures $(97.6 \pm 62.4 \mathrm{IU} /$ day compared with $118.7 \pm 59.4 \mathrm{IU} /$ day $(\mathrm{P}<0.05)$ ). Intakes of under $100 \mathrm{IU} /$ day were recorded in $58 \%$ of the patients and $41 \%$ of the controls $(P<0.05)$. Similarly, sunlight exposure was $24 \pm 34 \mathrm{~min} /$ day in the patients and $44 \pm 40$

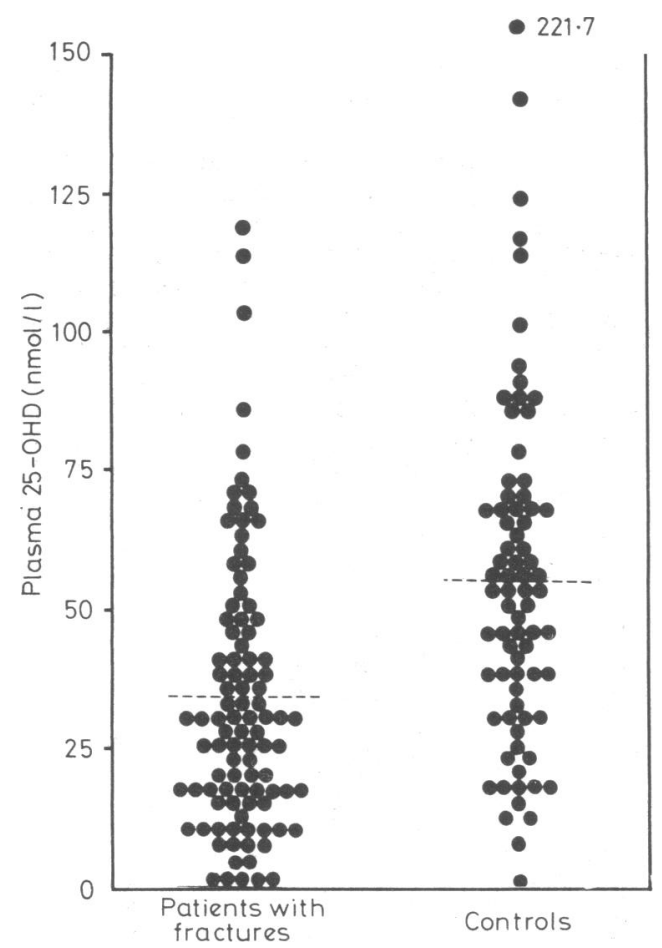

Plasma 25-OHD concentrations in elderly women with fractured neck of femur and controls matched for age and sex.

Horizontal dotted line represents mean values.

Conversion: SI to traditional units $-1 \mathrm{nmol} / 1 \approx 0.4$ $\mathrm{ng} / \mathrm{ml}$. $\min /$ day in the controls $(P<0.02)$. Just over half $(51 \%)$ the patients and $29 \%$ of the controls were housebound $(P<0.005)$.

In the fracture group plasma $25-\mathrm{OHD}$ concentration was more closely correlated with dietary vitamin $\mathrm{D}(\mathrm{r}=0.36 ; \mathrm{P}<0.001)$ than with sunlight exposure ( $r=0.18$; not significant). Conversely, in the controls, plasma 25 $\mathrm{OHD}$ was more closely correlated with sunlight exposure $(\mathrm{r}=\mathbf{0 . 4 2} ; \mathrm{P}<\mathbf{0 . 0 0 1})$ than with diet $(r=0.30 ; P<0.01)$.

\section{Comment}

Our data show clearly that low plasma 25-OHD concentrations are more common in patients suffering a fracture of the femoral neck than in matched controls. The figure of $40^{\circ}$, with $25-\mathrm{OHD}$ concentrations below $25 \mathrm{nmol} / 1(10 \mathrm{ng} / \mathrm{ml})$ - the level below which most cases of histological osteomalacia occur ${ }^{5}$-is consistent with the $30 \%$ prevalence of histological osteomalacia reported, ${ }^{2}$ since not all patients with vitamin $\mathrm{D}$ deficiency develop osteomalacia. Low dietary vitamin $\mathrm{D}$ and lack of sunlight both contribute to this deficiency but the latter is clearly the more important factor. The patients with fractures, $51^{\circ}$, of whom were housebound, depended for their vitamin D supply on their diet, which was inadequate. The controls, being more active, obtained their vitamin D from sunlight, which is why their plasma concentrations were relatively independent of their vitamin $\mathrm{D}$ intake.

We suggest that vitamin $\mathrm{D}$ deficiency contributes to the high incidence of fractures of the neck of the femur in Britain through an effect on the skeleton or on muscle power, or both. If this is so the rate of fractures to the femoral neck might be substantially reduced by improving the vitamin $\mathrm{D}$ status of the elderly population.

We are indebted to Professor I D G Richards for advice and to Mrs J Morris and Mrs A Davies for assaying plasma 25-OHD. Thanks are also due to Mr F Silk, Mr M Nelson, Mr M J Abberton, and Mr E B Longton for allowing us to investigate patients under their care.

${ }^{1}$ Knowelden, J, Buhr, A J, and Dunbar, O, British fournal of Preventive and Social Medicine, 1964, 18, 130.

${ }^{2}$ Aaron, J E, et al, Lancet, 1974, 1, 299.

3 Jenkins, D H R, et al, fournal of Bone and foint Surgery, 1973, 55B, 575.

${ }^{4}$ Morris, J F, and Peacock, M, Clinica Chimica Acta, 1976, 72, 383.

5 Peacock, $M$, personal communication.

(Accepted 5 fanuary 1979)

Department of Community Medicine and General Practice, University of Leeds

M R BAKER, MB, MRCP, registrar in community medicine

H MCDONNELL, MSC, MFCM, senior lecturer

MRC Mineral Metabolism Unit, General Infirmary, Leeds

M PEACOCK, FRCP, assistant director

B E C NORDIN, DSC, FRCP, director

\section{$\varnothing$ \\ Lepromatous leprosy and onchocerciasis}

Some recent reports ${ }^{1-3}$ mention a striking impairment of cellmediated immunity in heavily infected patients, especially in areas where onchocerciasis is hyperendemic. As a similar disturbance occurs in the lepromatous form of leprosy we tried to compare the prevalence of leprosy in districts with and without a high prevalence of severe onchocerciasis in the Republic of Upper Volta, in West Africa.

\section{Methods and results}

In Upper Volta national medical field services and the World Health Organisation Onchocerciasis Control Programme provide consistent data for both leprosy and onchocerciasis. We studied two populations: (a) that of 26 districts in the south of the country, where onchocerciasis is hyperendemic and the blindness rate higher than the national average of $1{ }^{\prime},{ }^{4}$ and $(b)$ that of 17 larger areas in the centre and north of the country which are largely free of onchocerciasis. For each district and area we calculated the percentage of the census population with leprosy and the percentage with lepromatous leprosy.

The results are shown in the table. Because the two populations studied 
Prevalence of leprosy and lepromatous leprosy in the two populations

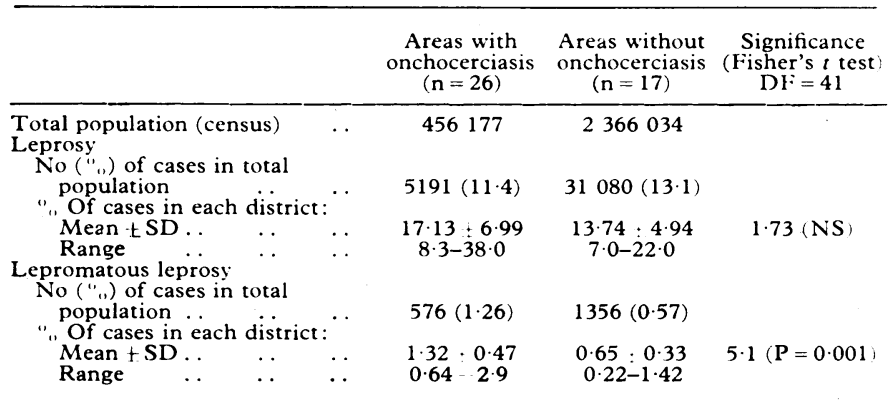

differed greatly in size we tested the difference in the prevalence of leprosy and lepromatous leprosy between the 27 southern districts and several random samples of the same size from the larger central and northern areas. In all cases results remained the same.

\section{Comment}

Our results indicate that in the two populations, in which the overall prevalence of leprosy is similar, the prevalence of lepromatous leprosy is about twice as high in the areas where onchocerciasis is hyperendemic.

This finding seems to agree with observations of a reduced level of immunity because of onchocerciasis and with the hypothesis that a highly infected patient with onchocerciasis is more likely to develop the lepromatous form of leprosy and any other infection.

${ }^{1}$ Buck, A A, Health and Disease in Chad. Baltimore, The Johns Hopkins Press, 1970.

2 Rougemont, A, et al, Lancet, 1977, 1, 309.

3 Bartlett, A, et al, Transactions of the Royal Society of Tropical Medicine and Hygiene, 1978, 72, 372.

${ }^{4}$ Prost, A, Distribution Cantonale des Aveugles en Haute-Volta-l map. Geneva, WHO, 1976.

(Accepted 14 December 1978)

\section{Ouagadougou, Upper Volta}

A PROST, MD, WHO epidemiologist

$M$ NEBOUT, $M D$, epidemiologist, Ministry of Health

A ROUGEMONT, MD, lecturer in tropical epidemiology, Aix-Marseille II University
51 female) with Graves's disease (12 secondary sulphonylurea failures requiring insulin more than three months from diagnosis, and 48 primary IDDs requiring insulin within three months of diagnosis) and 105 IDDs (21 male, 84 female) with thyroid failure ( 32 secondary sulphonylurea failures, and 73 primary IDDs). Of the patients with thyroid failure, 69 had confirmed primary hypothyroidism and 36 normal serum thyroxine concentrations but raised serum thyrotrophin concentrations. Group 2 comprised 164 IDDs (37 male, 127 female) who had normal serum thyrotrophin concentrations and no personal history of thyroid disease. Forty-six were secondary sulphonylurea failures, and 118 primary IDDs. There was no significant difference between the two groups in age at time of study or duration o diabetes (table). Statistical analysis was by $\%^{2}$ analysis.

The ocular fundi of each patient were carefully examined through dilated pupils under clinic conditions by one of us and the retinopathy state recorded as: 0 , no retinopathy; 1 , mild background retinopathy (small number of microaneurysms and occasional blot haemorrhage); 2 , moderate to extensive background retinopathy (large numbers of microaneurysms, blot haemorrhages, hard or soft exudates or both); 3, new vessel formation; and 4, blindness due to vitreous haemorrhage or retinal disorganisation, or both, after hacmorrhage or fibrosis.

Age, duration of diabetes, and retinopathy state of IDDs in groups 1 and 2 ( figures are numbers of patients)

\begin{tabular}{|c|c|c|c|c|c|c|c|c|c|c|}
\hline Age (years): & & & $<20$ & $20-29$ & $30-39$ & $40-49$ & $50-29$ & $60-69$ & $70-79$ & $80-89$ \\
\hline $\begin{array}{l}\text { Group } 1 \ldots \\
\text { Group } 2 \ldots\end{array}$ & $\begin{array}{l}\ldots \\
\cdots\end{array}$ & $\begin{array}{l}\cdots \\
\cdots\end{array}$ & 2 & $\begin{array}{l}3 \\
9\end{array}$ & $\begin{array}{l}15 \\
10\end{array}$ & $\begin{array}{l}24 \\
21\end{array}$ & $\begin{array}{l}47 \\
43\end{array}$ & $\begin{array}{l}49 \\
48\end{array}$ & $\begin{array}{l}21 \\
26\end{array}$ & $\begin{array}{l}6 \\
5\end{array}$ \\
\hline $\begin{array}{l}\text { Durations of } \\
\text { (years): }\end{array}$ & diabet & & $5-9$ & $10-14$ & $15-19$ & $20-24$ & $25-29$ & $30-34$ & $35-39$ & $>39$ \\
\hline $\begin{array}{l}\text { Group } 1 \ldots \\
\text { Group } 2 \ldots\end{array}$ & $\begin{array}{l}\cdots \\
\cdots\end{array}$ & $\begin{array}{l}\cdots \\
\cdots\end{array}$ & $\begin{array}{l}30 \\
22 \\
\end{array}$ & $\begin{array}{l}33 \\
28 \\
\end{array}$ & $\begin{array}{l}33 \\
35 \\
\end{array}$ & $\begin{array}{l}23 \\
27 \\
\end{array}$ & $\begin{array}{l}22 \\
25\end{array}$ & $\begin{array}{l}15 \\
17 \\
\end{array}$ & $\begin{array}{l}6 \\
6 \\
\end{array}$ & $\begin{array}{l}3 \\
4 \\
\end{array}$ \\
\hline Retinopathy & state: & & & 0 & 1 & 2 & 3 & 4 & & \\
\hline $\begin{array}{l}\text { Group } 1 \\
\text { Group } 2 .\end{array}$ & $\because$ & . & & $\begin{array}{l}86 \\
73\end{array}$ & $\begin{array}{l}43 \\
47\end{array}$ & $\begin{array}{l}22 \\
27\end{array}$ & $\begin{array}{l}13 \\
14\end{array}$ & $\begin{array}{l}1 \\
4\end{array}$ & & \\
\hline
\end{tabular}

The table gives the retinopathy states of patients in the two groups and shows no significant difference between them. Similarly, there was no significant difference between primary IDDs and secondary sulphonylurea failures in respect of retinopathy state when groups 1 and 2 were considered independently and combined.

\section{Comment}

There is increasing evidence for the existence of a primary autoimmune type of diabetes, whose characteristics include female preponderance, a later age of onset, over-representation of HLA-B8, and a high frequency of persistent islet-cell antibody. ${ }^{3}$ Close scrutiny of such a group of diabetics is clearly required, especially in respect of susceptibility to microangiopathy but the necessary inclusion criteria for primary autoimmune diabetes remain poorly defined. The presence of thyroid autoantibodies or a first-degree family history of thyroid disease or thyroid antibodies may not be sufficiently exacting as evidence of autoimmunity. For our study we have regarded only biochemical evidence of thyroid overactivity or underactivity as an index of primary autoinımune diabetes, and using this criterion have compared autoimmune (group I) and non-autoimmune (group II) IDDs of similar ages and durations of diabetes. No significant difference in the prevalerice or severity of retinopathy was observed in the two groups, suggesting that coincident autoimmune disease of a degree sufficient to produce thyroid failure or thyrotoxicosis neither protects against nor contributes to retinopathy. The latter is presumably the consequence of the cumulative metabolic disturbance found in insulin-dependent diabetes, although it may also depend on genetic influences. ${ }^{+}$

${ }^{1}$ Bottazzo, G F, et al, British Medical fournal, 1978, 2, 165.

2 Glick, S M, Metabolism, 1961, 10, 78

${ }^{3}$ Bottazzo, G F, et al, British Medical fournal, 1978, 2, 1253

' Pyke, D A, and Tattersall, R B, Diabetes, 1973, 22, 613.

(Accepted 15 fanuary 1979)

Diabetic and Dietetic Department, Royal Infirmary, Edinburgh EH3 9YW

R S GRAY, MRCP, senior registrar

B F CLARKE, FRCP, consultant physician

\section{Patients, methods, and results}

The patients were divided into two groups according to the presence or absence of coincident thyroid disease. Group 1 comprised 60 IDDs $(9$ male,



